\title{
Review Article \\ Transferrin: Endocytosis and Cell Signaling in Parasitic Protozoa
}

\author{
Magda Reyes-López, Carolina Piña-Vázquez, and Jesús Serrano-Luna \\ Centro de Investigación y Estudios Avanzados del IPN, Apartado Postal 14-740, 07000 México, DF, Mexico
}

Correspondence should be addressed to Magda Reyes-López; magda.magrel2003@gmail.com

Received 9 September 2014; Accepted 18 December 2014

Academic Editor: Jung-Hsiang Tai

Copyright (C) 2015 Magda Reyes-López et al. This is an open access article distributed under the Creative Commons Attribution License, which permits unrestricted use, distribution, and reproduction in any medium, provided the original work is properly cited.

\begin{abstract}
Iron is the fourth most abundant element on Earth and the most abundant metal in the human body. This element is crucial for life because almost all organisms need iron for several biological activities. This is the case with pathogenic organisms, which are at the vanguard in the battle with the human host for iron. The latest regulates Fe concentration through several iron-containing proteins, such as transferrin. The transferrin receptor transports iron to each cell that needs it and maintains it away from pathogens. Parasites have developed several strategies to obtain iron as the expression of specific transferrin receptors localized on plasma membrane, internalized through endocytosis. Signal transduction pathways related to the activation of the receptor have functional importance in proliferation. The study of transferrin receptors and other proteins with action in the signaling networks is important because these proteins could be used as therapeutic targets due to their specificity or to differences with the human counterpart. In this work, we describe proteins that participate in signal transduction processes, especially those that involve transferrin endocytosis, and we compare these processes with those found in T. brucei, T. cruzi, Leishmania spp., and E. histolytica parasites.
\end{abstract}

\section{Iron}

Iron $(\mathrm{Fe})$ is a cofactor of a variety of proteins with important functions for almost all living organisms, prokaryotes, and eukaryotes. Fe is important for several biological processes, such as breathing, oxygen transport, the tricarboxylic acid cycle, gene regulation, and DNA synthesis [1]; however, this element presents high toxicity potential for biological macromolecules [2-6]. Therefore, maintaining cellular Fe concentration requires precise mechanisms to regulate its uptake and storage.

In a normal diet, Fe absorption is approximately $1.5 \mathrm{mg}$ every day. Fe absorption is accomplished through complex mechanisms that are carried out by enterocytes in the upper part of the gut, the duodenum, and the proximal jejunum. The Fe absorbed can be nonhaem Fe or haem Fe. The Fe absorption mechanism involves several import proteins for the two ionic forms of iron, $\mathrm{Fe}^{2+}$ and $\mathrm{Fe}^{3+}$. Haem Fe from haemoproteins is an important Fe source in omnivores; this is more easily absorbed than nonhaem $\mathrm{Fe}$ from vegetables and grains $[3,6]$.
In the enterocyte, $\mathrm{Fe}$ can have several destinations. The $\mathrm{Fe}$ destination depends on the iron pool inside the cell. Therefore, $\mathrm{Fe}$ can be exported from cells to the circulatory system or can be accumulated inside the cell. For Fe that is exported to the circulatory system, a protein specific for this purpose, ferroportin1, has been identified. Ferroportinl is a multipass protein found in the basolateral membrane of enterocytes. Once exported by ferroportinl, Fe must be transformed in a process coupled by reoxidation of $\mathrm{Fe}^{2+}$ to $\mathrm{Fe}^{3+}$ by ferroxidases, such as ceruloplasmin, and followed by the loading of $\mathrm{Fe}^{3+}$ onto transferrin (Tf). These proteins are able to regulate iron efflux and consequently iron absorption, because overexpression of ferroportinl is induced by cellular Fe and is suppressed by hepcidin, which inhibits Fe efflux through binding to and induction of the degradation of ferroportin1 $[3,6]$.

Cellular Fe metabolism is regulated by Fe itself. When Fe is at low concentrations, iron regulatory proteins 1 and 2 (IRP1 and IRP2), which are components of posttranscriptional regulation, bind to iron responsive elements (IREs) present in the untranslated regions of the mRNAs encoding TfR1, stabilizing it and increasing the number of receptors in 
the membrane and Fe levels; when Fe levels are high, ferritin synthesis increases, and the receptor mRNA is destabilized, leading to low Fe entry [7-9].

In the blood, Fe bound to Tf, which is the main protein for transporting Fe in plasma, regulates Fe levels in biological fluids. Although Fe is the most essential nutrient for almost all organisms, it has a poor bioavailability and very low solubility and is not found free in nature; therefore, all organisms have invested significant efforts in obtaining Fe.

\section{Transferrin}

Fe exported to the serum is scavenged by Tf, a glycosylated $\mathrm{Fe}^{3+}$-binding protein, which is found in blood plasma, lymph, and other body fluids and has as its primary function the transportation of Fe to all cells. Another function of Tf is to keep free $\mathrm{Fe}$ at a very low concentration, approximately $10^{-18} \mathrm{M}$, avoiding the high potential risk of damage and depriving pathogens of $\mathrm{Fe}$, which they require for growth. Tf has an important impact in the defense against infections [10].

Tf is a single polypeptide of about $80 \mathrm{kDa}$ with two homologous lobes ( $\mathrm{N}$ - and $\mathrm{C}$-terminal) connected by a short center region. Normally, only $30 \%$ of the binding sites of the protein are occupied by ferric $\mathrm{Fe}\left(\mathrm{Fe}^{3+}\right)$. Tf binds one $\mathrm{Fe}^{3+}$ ion in each of the two lobes; the $\mathrm{C}$-terminal lobe binds $\mathrm{Fe}$ more tightly and releases it more slowly. Iron binding requires binding of a carbonate/bicarbonate anion in a synergistic way. A complete series of reviews about Tf have been published recently in a special issue of Biochimica et Biophysica Acta (BBA), general subjects entitled Transferrins:Molecular mechanisms of iron transport and disorders 1820(3), 2012.

Serum Tf is synthesized in the liver, central nervous system, testes, ovaries, spleen, mammary glands, and kidneys. Tf is a very highly conserved protein found from bacteria to mammals, including algae [11-14]. Interestingly, Tf is absent in nematodes [15], and unfortunately there is no evidence of the presence of this protein in parasitic protozoa.

\section{Transferrin Receptors from Mammalian Cells}

Cells take up Fe bound to Tf using Tf receptors (TfR); thus, the biological function of the specific receptors is to bind Tf on the cell surface and ingest it. TfRs are a member of the family of tyrosine kinase-linked receptors that possess an intrinsic tyrosine kinase involved in signaling pathways.

Two TfRs have been described in mammals, TfR1 with high-affinity uptake for holoTf and currently the most studied and TfR2 that binds Tf with a 25-fold lower affinity; both TfRs are homodimeric transmembrane glycoproteins that are specific for Fe-loaded Tf (holoTf) [16]. TfR2 shares 45\% amino acid sequence identity with TfR1 and plays a critical role in iron homeostasis, with a minor participation in $\mathrm{Fe}$ uptake [17].

At low $\mathrm{Tf}$ concentrations of $<0.3 \mu \mathrm{mol} / \mathrm{L}$, TfR1 mediates Tf internalization, but at high Tf concentrations, low affinity uptake of holoTf that is not mediated by TfR1 has been observed. TfR2 has been proposed as a receptor that participates in this low affinity uptake, but this receptor is expressed in only a few organs, and the low affinity uptake is found in more cells. Other proteins are responsible for binding and internalize Tf with low affinity, such as the proteoglycans via fluid phase endocytosis in hepatocytes and glyceraldehyde3-phosphate dehydrogenase $(\mathrm{GAPDH})$ on the macrophage cell surface $[10,18,19]$. It is important to note that several proteins, especially glycolytic enzymes, have been identified with multifunctional properties in both prokaryotic and eukaryotic cells. One of these new functions is to bind Tf in order to obtain Fe [20, 21].

TfR1 is a homodimer linked by two disulfide bridges with a molecular mass of $190 \mathrm{kDa}$. The receptor is formed by 3 domains: transmembrane, cytoplasmic, and extracellular, which is the larger one and contains the Tf binding site $[9,10,22]$.

Tf internalized by both high and low affinity uptake receptors is transported to early endosomes as described below. Once Tf binds to the extracellular domain of the TfR on the plasma membrane, it changes conformation and dimerizes, and this change allows the activation of kinase activity, and it becomes phosphorylated. The Tf-TfR complex enters the endocytic pathway via endocytosis mediated by clathrincoated pits. The action of dynamin is crucial for the fission of pits from the plasma membrane and the formation of coated vesicles. The Tf-TfR complex is transported to a unique endosomal compartment where acidification ( $\mathrm{pH}$ lower than 5.6) leads to the release of ferric iron in 2-3 $\mathrm{min}[3,23]$.

Successively, Tf without Fe (apoTf) bound to the receptor is transported to the plasma membrane via endocytic recycling compartments (ERC). The receptor becomes dephosphorylated, and apoTf is released outside the cell in order to bind new Fe $[16,17,24]$. All proteins involved in signal transduction depend on receptor activation produced by the binding of the ligand $[25,26]$.

Tf, through the TfR, acts as a growth factor. Therefore, its function is important for the regulation of embryogenesis, cell growth, motility, proliferation, differentiation, glucose metabolism, and apoptosis and is determined by its trafficking through the endosomal pathway [27].

In the same way as in mammalian cells, TfR from parasites increases the uptake of Tf, and in consequence of Fe, through the expression of a specific receptor or binding protein that is associated with the course of the infection. TfRs are very important determinants of virulence in pathogens, and depending from the environment where the infection takes place the receptor is or is not expressed. In this sense, parasites in blood vessels express TfR to bind Tf present in this environment, even more in other environments where the presence of this receptor will not be expected: like inside cells, some parasites express TfR, such as Leishmania, and it has been demonstrated that this parasite developed strategies to increase the presence of Tf inside the parasitophorous vacuole where Leishmania lives. These elaborated systems of $\mathrm{Fe}$ obtained by TfR expression ensure their success as parasites, host colonization, and the establishment of the infection. 


\section{TfR in Protozoan Parasitic Organisms}

A successful infection by pathogens relies on the host colonization. Colonization depends on the availability of nutrients and growth factors, such as Fe. The relationship between parasitic organisms and their hosts is especially complex, because the hosts must obtain $\mathrm{Fe}$ from the diet and fulfil their own $\mathrm{Fe}$ needs and at the same time sequester this nutrient away from invading pathogens. Tf is the iron-containing protein that fulfils this activity, but protozoan parasites do not express Tf or Tf-like proteins that help them to acquire Fe. As these organisms are highly dependent on a plentiful supply of host Fe, they have developed mechanisms to acquire this metal by multiple and divergent pathways or steal it from host Fe deposition sites $[1,28]$.

These mechanisms include the secretion of specific Tf proteases, the presence of reductases that capture host Fecontaining proteins, or through specific TfR or Tf binding proteins [29]. The presence of TfR to piracy Fe must be effective enough to ensure parasites pathogenic potential and proliferation.

TfRs have been described in Plasmodium spp. [30, 31], Tritrichomonas [32], trypanosomatids such as Trypanosoma brucei [33], Trypanosoma cruzi [34] and Leishmania spp. [35], and the amoeba Entamoeba histolytica [36]. It is remarkable that these parasites express receptors that function similarly and recognize the same carrier proteins as the mammalian cell, even though some of them are structurally different and others utilise a completely different mechanism despite their similar function.

The use of specific receptors to obtain growth factors or nutrients ensures temporal prolongation of signal transduction initiated upon ligand binding at the plasma membrane and continued after internalization. In this review, the TfRs from parasites, mainly those with signal transduction studies, have been included and compared with what is known in mammalian cells.

Trypanosoma brucei. African trypanosomiasis is caused by the protozoan Trypanosoma brucei. This is a very important disease, because millions of people are at risk of infection and because current chemotherapies are toxic $[37,38]$.

The cell cycle of this protozoan consists of two general stages, one in humans and the other in the insect vector, the tsetse fly (genus Glossina). The initial infection is in the gut of the fly (procyclic stage). The infection travels to the salivary glands, and the parasite differentiates into the epimastigote stage and then to the metacyclic stage. This is the stage in which the parasite is injected into the mammalian host. The parasite lives within the mammalian bloodstream as its slender form, and when it is necessary, the parasite transforms into the stumpy form as a prelude to another insect infection [39]. In the bloodstream stage, this parasite is confronted by severe conditions of Fe scarcity. The sole source of iron provided by the host is available as Tf.

Therefore, bloodstream forms of T. brucei express a Tf receptor ( $\mathrm{Tb} \mathrm{TfR}$ ) that mediates $\mathrm{Tf}$ endocytosis at the plasma membrane; this receptor has already been identified and is structurally completely different from the host $\operatorname{TfR}[33,35,40$,
41]. TbTfR is formed by a complex of the proteins encoded by two expression site-associated genes, ESAG6 and ESAG7. ESAG6 has a glycosylphosphatidylinositol (GPI) anchor that attaches the receptor to the plasma membrane. The binding of Tf requires the association of both ESAG proteins [42, 43]. ESAGs are cotranscribed with the gene encoding the variant surface glycoprotein (VSG) of the surface coat of the parasite. VSGs display the adaptation mechanism of antigenic variation [44]. This process allows the development of sustained infections.

Most trypanosomatid protozoa have a specific structure that allows uptake of nutrients at a specific membrane site, named the flagellar pocket. This is a cell membrane invagination from which the flagellum emerges. In this structure, endocytosis of Tf takes place [45]. The molecular mechanism for Tf internalization is through a dissimilar mechanism to that observed in mammals.

When Tf binds to the TbTfR anchored to membrane by the GPI tail, it is internalized by clathrin-dependent endocytosis. The low $\mathrm{pH}$ of the endosome allows the release of $\mathrm{Fe}$ from Tf. Tf at this $\mathrm{pH}$ has a low affinity for the TbTfR [40] and is released and transported to lysosomes for degradation by the action of the T. brucei cysteine-protease rhodesain or cathepsin L activity (TbCATL) and TbCATB (T. brucei cathepsin B) $[33,46]$. TbTfR is recycled to the cell surface to bind new Tf and the Fe associated with it [41, 47]. The main difference with mammalian cells is that the Tf is maintained attached to the receptor and transported to the extracellular medium in order to bind new Fe. However, the degradation of $\mathrm{Tf}$ in parasites could be for nutritional purposes.

The TfR is of great importance for parasite adaptability and for the ability to colonize several hosts. Because TbTfR has a low-specificity for Tf, the parasite can use Tf from different sources providing the parasite the opportunity to increase its number of hosts, including humans and cattle $[44,48]$. The use of $\mathrm{Tf}$ from different sources is important for the diversification of species that can be infected by parasite organisms.

Trypanosoma cruzi. T. cruzi is an intracellular protozoan, the causal agent of South American trypanosomiasis or Chagas disease, which infects 8 million people in Latin America [49].

Similar to the T. brucei parasite, T. cruzi infects humans and invertebrates hosts during defined stages of the life cycle. The invertebrate host is the triatomine bug that ingests trypomastigotes present in the bloodstream of an infected mammalian host when it feeds. In the gut of the vector, the parasites transform into epimastigotes and migrate to the posterior gut. Then, they transform into infective trypomastigotes, and the vector inoculates them subcutaneously into the mammalian host with infective feces. Once inside, parasites invade several kinds of cells through a lysosomemediated mechanism, differentiating into amastigotes that replicate and transform into trypomastigotes causing host cell lysis that releases parasites into the bloodstream; the parasites are then capable of invading other cells or infecting vectors that make a meal of the host [50].

T. cruzi amastigotes growing in cell-free medium and epimastigotes require high concentrations of Fe to survive, 
and curiously in these stages, they are able to obtain Fe from human Tf. Amastigotes present specific TfR in the flagellar pocket [51] that are not present in the trypomastigote form. TcTfR presents structural homology with human TfR, with a $200 \mathrm{kDa}$ molecular mass, and Tf is internalized by receptor-mediated endocytosis. However, in the epimastigote stage of the life cycle, the parasite ingests Tf at the cytostome/cytopharynx through a TfR [52]. This structure is a membrane invagination that is similar to the flagellar pocket, but the cytostome reaches deeply into the cytoplasm in the direction of the nucleus. The Tf receptor-mediated uptake is through small, uncoated vesicles to the reservosomes [52]. The participation of uncoated vesicles suggests that the TfR is not recycled to the membrane $[34,53]$.

Despite the fact that this parasite has clathrin that could participate in endocytosis [54, 55], morphological studies have demonstrated that $\mathrm{Tf}$ internalization is carried out through a clathrin-independent and cholesterol-dependent endocytosis pathway. This pathway was identified by the utilization of specific inhibitors of endocytic pathways. Clathrindependent internalization similar to that of T. brucei should not be excluded; the cholesterol-dependent pathway could be a secondary endocytic process, because inhibition of this pathway did not reduce cell proliferation $[34,56]$. Correct Tf internalization requires the association of the cytostome with the flagellar complex in a way that is not well understood [57]. It would be interesting to know whether this route of Tf entry is constitutive or if it depends on the stage of the life cycle of the parasites, because the trypomastigote is the natural form that would confront human Tf.

Leishmania spp. The leishmaniases and fatal visceral leishmaniases are diseases with a large spectrum of clinical symptoms in mammals and are caused by at least 20 pathogenic obligate intracellular species that include Leishmania major, L. infantum, L. braziliensis, L. mexicana, L. amazoniensis, $L$. tropica, and $L$. donovani. Approximately 2 million new cases occur every year with an estimated 150 million people infected worldwide $[58,59]$.

The infection starts with the bite of an infected sand fly (dipteran insects) that inoculates metacyclic promastigotes (infective form) into a mammalian host. After being phagocytosed by macrophages, the parasites are found inside parasitophorous vacuoles (PVs); these acidic structures are similar to phagolysosomes and contain certain lysosomal enzymes. Inside the PVs, promastigotes transform into amastigotes. The parasites replicate and induce cell lysis; released parasites can be phagocytosed by adjacent macrophages or infect the surrounding cells. Sandflies become infected by ingesting infected cells during blood meals; amastigotes transform into promastigotes in the gut and then migrate to the proboscis for a new round of infection $[60,61]$.

Once the parasites are released and before the promastigotes are phagocytosed, they could be encountering Tf from the bloodstream; thus, the expression of a specific receptor would be useful. The presence of a specific and saturable TfR similar to the mammalian TfR was described in promastigotes. The TfRs of $L$. infantum (LiTfR) and L. major
( $L m \mathrm{TfR}$ ) were described as an integral membrane monomeric glycoprotein of $70 \mathrm{kDa}$ that is structurally different from the mammalian receptor [35]. In both developmental forms of $L$. chagasi, promastigotes and amastigotes, the binding of $\mathrm{Tf}$ is through nonspecific and saturable Tf binding proteins [62]. Unfortunately, the $\mathrm{Tf}$ endocytic process used by this parasite has not been described.

Leishmania amastigotes are usually the form internalized by the mammalian host cell, but in the case of $L$. amazoniensis promastigotes [60], they can also be internalized and then be able to survive and establish within PVs. Promastigotes and amastigotes inside the PV face conditions that include extremely restricted access to essential $\mathrm{Fe}$, and Leishmania parasites have developed several strategies for surviving inside the mammalian host. One strategy consists of fusion of the PV with several individual vacuoles and fusion of the resultant vacuoles with compartments of the endolysosomal system. This was discovered because proteins specific for each of the vacuoles are found associated with PVs $[60,63]$. In this form on the tenth day of infection, the mammalian Tf-TfR complex normally found in early and recycled endosomes is associated with the PV [64]; furthermore, Tf was found to be delivered to PV and then endocytosed by intracellular amastigotes, so it could be possible that infection time enhances the endosomal delivery to the PV [63]. The iron obtaining mechanisms could be different depending on the Leishmania species, because in L. mexicana-infected macrophages $\mathrm{Tf}$ was not present in the PV [64]; however, amastigotes survive in this environment suggesting the presence of an alternative iron source.

Leishmanial infection would also affect the TfR recycling regulation on macrophages [64], resulting in a Tf disorder where Tf could reach other late or lysosomal compartments and probably be transported to PVs.

Once the Tf is endocytosed by Leishmania intracellular parasites, it is delivered to the cysteine proteinase-rich compartments, where this protein is degraded [63].

Another strategy to obtain iron inside the acidic PV from the Tf-TfR complex could present a similar behaviour as in the endosomes; that is, the Tf loses affinity for Fe and remains attached to the receptor and iron release could be facilitated via Tf degradation by cysteine proteases secreted by living amastigotes or released by the lysis of the dead parasites [63]. Then, this element is transported by means of a parasiteassociated or -secreted reductase like the Leishmanial iron transporter 1, LIT1, which plays an important role in $\mathrm{Fe}$ acquisition by converting $\mathrm{Fe}^{3+}$ into $\mathrm{Fe}^{2+}$ for transmembrane transport and allowing Fe to be internalized by the parasite $[32,61,65]$. This iron transporter provides enough Fe for the intracellular growth and virulence of Leishmania.

Entamoeba histolytica. E. histolytica is a parasitic protozoan of humans. It causes amoebiasis, a global disease characterized by dysentery and intestinal ulcer production. Under certain conditions, the parasite is able to invade the liver, lungs, and brain. E. histolytica infects 500 million people, causes disease in 50 million people, and causes death in 100,000 people each year [66]. 
E. histolytica has an absolute necessity of Fe. This need in the bowel can be sustained by bacteria or phagocytosed red blood cells or through endocytosis of Fe-containing proteins from the host. During invasive amoebiasis, the Fe source is Tf in the bloodstream and liver; in this organ, the use of ferritin, an Fe-storage protein, would be useful for the parasite.

The amoeba has developed two specific mechanisms for obtaining Fe from $\mathrm{Tf}[36,67]$ to ensure it obtains the Fe needed for colonization and infection. One mechanism is by receptor-independent internalization which is active at high Tf concentrations (micromolar range) [68], and at low Tf concentrations between 1.1 and $5.6 \mathrm{nM}$, the internalization is through specific EhTfbps of 70, 96, and $140 \mathrm{kDa}$ molecular mass as previously described [67]. Similar to mammalian cells, Tf is internalized by two mechanisms with differing affinity depending from the Tf concentration. More studies must be performed to determine the relationship between the presence of a specific receptor with low or high binding affinity for Tf and Fe necessity.

The EhTfbps identified present structural homology with the human TfR, because this is recognized with an antihuman TfR antibody. Similarly, T. cruzi Tf receptor is recognized with the same antibody, while TbTfRs are different proteins not recognized by human TfR antibodies. EhTfbps form a complex with holoTf and are endocytosed with the participation of clathrin $[67,69,70]$. Tf is transported into the endolysosomal system (unpublished results).

The $96 \mathrm{kDa}$ EhTfbp was identified as enzyme acetaldehyde/alcohol dehydrogenase-2 (EhADH2) [67]. The other EhTfbps have not been identified (70 and $140 \mathrm{kDa})$. This enzyme is essential for the growth and survival of E. histolytica and allows the parasite to obtain energy through glucose fermentation and to convert acetyl-CoA into ethanol. This enzyme binds extracellular matrix proteins and is found on the cell surface and in the cytoplasm [71]. This protein may be participating in binding Fe from Tf, because in the absence of Fe (apoTf), it does not bind Tf.

In this parasite, other glycolytic enzymes have been described with several functions, such as enolase, which interacts with the activity of the Ehmeth enzyme that catalyzes DNA methylation [72].

As previously described, surface-localized GAPDH has a novel function with TfR in human and murine macrophage cell lines [19]. GAPDH is capable of interacting with Fe bound to Tf. This enzyme forms a complex with Tf and is taken to early endosomes. The same enzyme with a similar function was reported in Staphylococcus aureus and Staphylococcus epidermidis, bacteria capable of removing Fe from Tf via a receptor-mediated process [73]. Interestingly, these enzymes bind proteins from the extracellular matrix, like fibronectin and laminin, in addition to plasminogen, plasmin, lysozyme, myosin, and actin $[19,73,74]$. These proteins have been termed moonlighting or multifunctional proteins [21] due to their ability to have more than one function. Other glycolytic enzymes with multiple functions unrelated to their role in glycolysis are $\alpha$-enolase, lactate dehydrogenase, and hexokinase [20].
The life cycle of protozoan parasites suggests why these organisms require an extensive network of cell surface signaling molecules. For example, E. histolytica has to compete with bacteria for $\mathrm{Fe}$, other nutrients, and space in the intestinal microenvironment, and intra- or extracellular trypanosomatids in the mammalian host must obtain $\mathrm{Fe}$ and other nutrients that are present in very low concentrations. In addition, these parasites must sense several stressors to regulate the different stages of their life cycle to evade host defenses or control their invasive behaviour. Upon invasion, parasites continue to face a battery of challenges that require the ability to adhere and obtain sufficient nutrients. The survival of these parasites within their host requires a profound ability to sense and respond to environmental challenges, and utilization of an extensive signaling network may therefore be very useful.

\section{Internalization Pathway and Signal Transduction Pathway}

Despite the fact that there is much information about TfR signaling pathways in mammalian cells, very little information is available in protozoan parasites, despite the fact that this pathway regulates proliferation and cell growth. In describing these pathways, the emphasis will be placed on the Tf-TfR complex in mammalian cells and the way in which information travels from the cell surface to the cytosol in comparison with that observed in protozoa.

Tf trafficking of information inside the cell and initiation of several signaling pathways are very well defined in mammalian cells: (1) trafficking and insertion of membrane vesicles, (2) inositol-1,4,5-triphosphate and diacylglycerol signaling pathway, (3) MAPK signaling pathway, and (4) growth factors signaling pathway (Figure 1).

5.1. Trafficking and Insertion of Membrane Vesicles. The initial signal propagation is in the plasma membrane for endocytosis and then through the endocytic compartments [27, 75-79]. Endocytosis of the Tf-TfR complex is regulated by the concentration of phosphatidylinositol 4,5-bisphosphate $\left(\mathrm{PI} 45-\mathrm{P}_{2}\right)$ in the plasma membrane, which induces the recruitment of clathrin and its adaptor protein AP-2 [80, 81]. The processes of invagination and scission of the clathrincoated pits are regulated by actin and actin-binding proteins [82-85] that increase the affinity for the dynamin 2 GTPase, Dyn2, which induces scission of the pit [84] to be posteriorly transformed into early endosomes $[25,27,77,78,86]$.

Vesicle formation results in spatial and temporal compartmentalization that is controlled by Rab proteins, members of the small GTPase family, which are involved in transmitting signals and providing the identity of the endosome. Tf-TfR complexes accumulate in early endosomes that are specifically marked with Rab5, early endosome antigen 1 (EEA1) [25, 87], and phosphatidylinositol-3,4,5-triphosphate (PI-3,4,5-P3) [26, 75, 88, 89]. Later, complexes are transported to endocytic recycling compartments (ERCs), which present Rab4 [90] and Rab11 [91], where apoTf-TfR and other recycling proteins are concentrated. ERCs are concentrated in close proximity to the nucleus and around the microtubuleorganizing center $[92,93]$. 


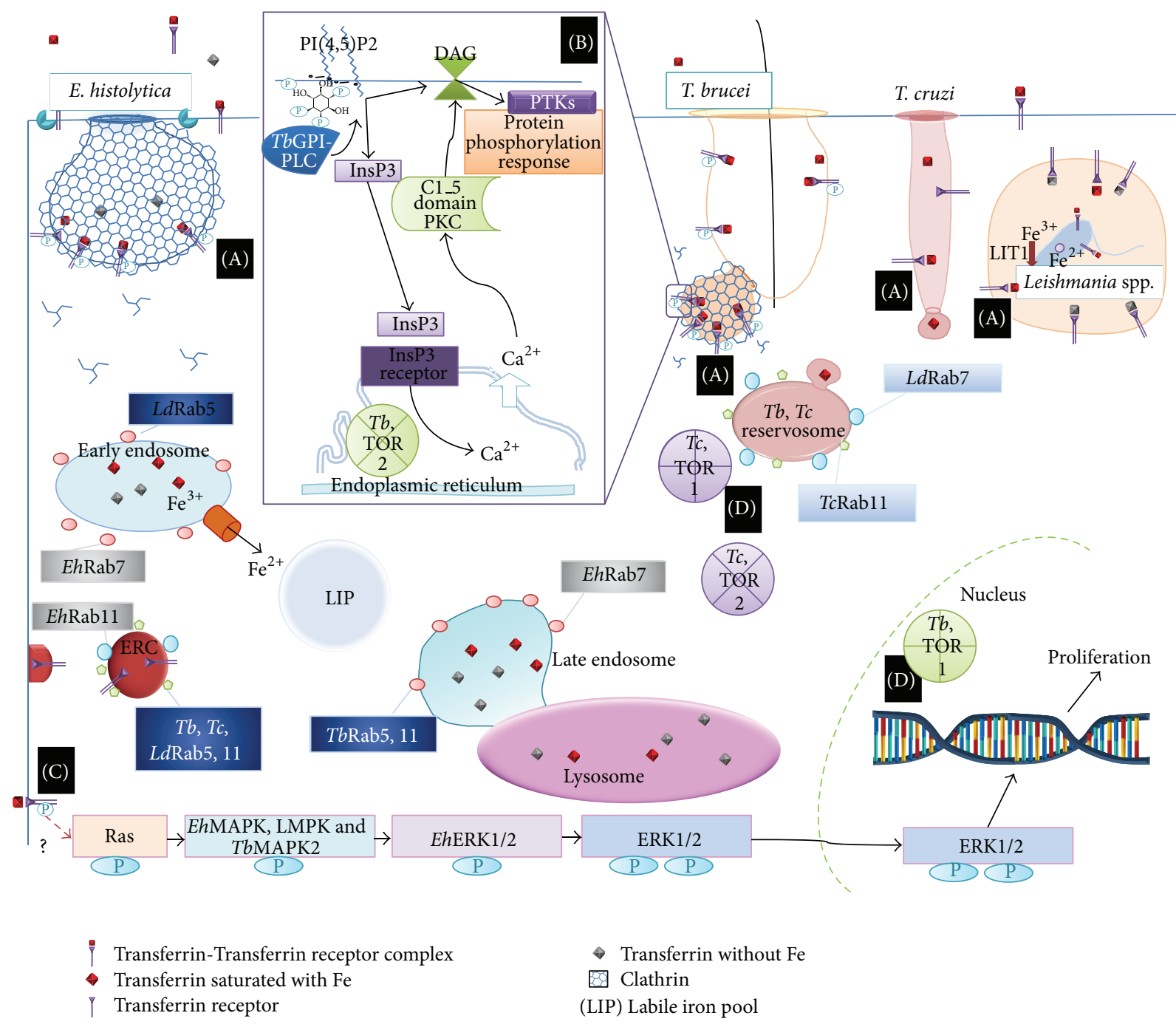

FIGURE 1: Transferrin endocytosis and signaling pathways in protozoan parasites. (A) Trafficking and insertion of membrane vesicles. The Tf-TfR complex is endocytosed in clathrin coated vesicles in T. brucei and E. histolytica but in noncoated vesicles in T. cruzi. The monomeric G proteins, Rabs, play a role in controlling the trafficking and insertion of new vesicles into endosomes or with endocytic recycling endosomes (ERCs) that recycle the receptor in T. brucei and Leishmania; in the case of T. cruzi, the receptor is not recycled back to the membrane. (B) Inositol-1,4,5-triphosphate and diacylglycerol signaling pathway. In T. brucei and Leishmania, TfR activation stimulates the formation of InsP3 and DAG through the action of GPI-PLC. Insp3 produces $\mathrm{Ca}^{2+}$ release from the endoplasmic reticulum to stimulate cell proliferation. Ca ${ }^{2+}$ in the cytoplasm binds to calmodulin (CaM) and translocates into the nucleus. DAG activates PKC, which then phosphorylates proteins that generate a specific response. (C) MAPK signaling pathway. TfR activated by Tf binding results in phosphorylation of MAPK, which has a central role in cell proliferation, and phosphorylation of the ERK1/2 kinases, which then translocate into the nucleus to activate transcription factors. These types of kinases are described in E. histolytica, T. brucei, and Leishmania. (D) Growth factor signaling pathway through TOR. Active PI3K takes information to TOR complexes that regulate protein synthesis by phosphorylation. TOR kinase functions are well conserved in eukaryotes with some differences in cellular localization in T. brucei and T. cruzi.

Actin regulators [92] and other proteins that function in membrane tubulation and fission [94], together with microtubules, are involved in endosome and ERC transportation $[95,96]$. Also, specific vesicle-associated membranes (SNARE) proteins that mediate vesicle fusion [97] are important for binding membranes from different vesicles.

In T. brucei, the Tf-TbTfR complex is endocytosed in clathrin-coated vesicles [45], and its adaptor protein, TbEpsinR, instead of AP-2 from mammals, promotes clathrin assembly. Additionally, in trypanosomes the endocytosis and scission of the clathrin-coated pits are independent of dynamin [98] (Figure 1, (A)).

Endocytosis in unicellular parasitic protozoa is regulated by the Rab family of proteins. In T. cruzi, Tf is transported to reservosomes, structures that are similar to late endosomes, which present TcRAbll [54]. In T. brucei, the TbTfR is recycled back to the flagellar pocket [99] in a recycling system that involves two isoforms of Rab5 (TbRab5A and TbRab5B), and TbRabl1 [100]. A similar process occurs in T. cruzi and Leishmania, where Rab5, identified based on its homology 
with TbRab5 [101] and Rab11, may be participating in the recycling of receptors [102], but it is not known in which kind of endosomes they are present exactly. Tf is transported to lysosomes for degradation. Interestingly, in the procyclic stage of $T$. brucei in the invertebrate host, the two Rab5 isoforms occupy the same compartment and have similar effects but in the fluid-phase endocytosis. The differences in endocytic regulation between the two stages of the parasite life cycle show the different mechanisms for surviving in two different hosts: insects and mammals $[103,104]$.

In the parasite E. histolytica, EhRabllA and EhRabllB may be participating in the recycling of receptors, because these Rablls are observed in cells during Fe starvation conditions and in the beginning of the encystation process [105-108]; in addition, these EhRablls participate in secretion of cysteine proteases [109].

In Leishmania, Rab7 protein promotes fusion with the late endosome during trafficking [110], but $L d \mathrm{Rab} 7$ is present in Golgi cisternae, and E. histolytica EhRab7A is found in endosomes [111]. In the latter protozoan, a genetic screen established the presence of more than 100 Rabs [112], 75\% of which are unique to the genus and called RabX, such as EhRabX3 [113], for which the crystallization and preliminary $\mathrm{X}$-ray diffraction analysis were performed. Despite the differences observed, Rab-mediated vesicular trafficking is a wellconserved process in parasitic protozoa.

\subsection{Inositol-1,4,5-Triphosphate and Diacylglycerol Signaling} Pathway. The inositol-1,4,5-triphosphate and diacylglycerol signaling pathway is another important signaling pathway activated by $\mathrm{Tf}$ internalization. In this pathway, $\mathrm{Ca}^{2+}$ signaling plays a key role in controlling the process of cell proliferation. Tf bound to TfR, a type of tyrosine kinaselinked receptor, stimulates the formation of inositol-1,4,5triphosphate $\left(\mathrm{InsP}_{3}\right)$ and diacylglycerol (DAG) through the hydrolysis of phosphatidylinositol-4,5-diphosphate (PI-4,5P2) by phospholipase C (PLC). The released DAG has an important role activating protein kinase $\mathrm{C}(\mathrm{PKC})$ and the Ins $\mathrm{P}_{3}$ diffuses into the cytosol to activate $\mathrm{InsP}_{3}$ receptors to release $\mathrm{Ca}^{2+}$ stored in the endoplasmic reticulum. The Ins $\mathrm{P}_{3} / \mathrm{Ca}^{2+}$ signaling system controls many different cellular processes, such as proliferation [114-116].

This kind of signaling pathway has been described only in T. brucei and Leishmania. In these parasites, Tf internalization is specifically regulated by glycosylphosphatidylinositolphospholipase C (GPI-PLC). This enzyme is expressed in the bloodstream form of T. brucei. During transformation to the insect stage, GPI-PLC contributes to the release of VSG from the plasma membrane. A new function of the enzyme has been described as a signaling protein that stimulates endocytosis. Similar to that observed in mammalian cells, the products of the enzyme activity are DAG and inositolphosphoglycans (IPG). DAG regulation of Tf internalization depends on proteins with specific domains to act as DAG receptors with protein tyrosine kinase (PTK) and ubiquitin ligase domains [117]. Through the PTK domain, Tf endocytosis is regulated by phosphorylation of the components of the endocytic machinery, such as clathrin, actin, or SNARE proteins. In these organisms, phosphorylation depends on PTKs rather than the Ser/Thr kinases (PKCs) present in vertebrates [117, 118] (Figure 1, (B)).

5.3. MAPK Signaling Pathway. Early endosomes and ERCs function as structures for protein assembly in this signaling pathway. The classical example of a protein phosphorylation cascade, highly conserved in eukaryotic organisms, is the mitogen-activated protein kinase (MAPK) pathway that consists of activation of tyrosine kinase-linked receptors, resulting in the phosphorylation of extracellular signalregulated kinases $1 / 2(\mathrm{ERK} 1 / 2)$ that then translocate into the nucleus. This pathway often begins with Ras, another member of the small GTPase family, and its function is the control of many cellular processes, particularly those related to cell proliferation.

Variability in the levels of expression or activity of MAPKs has been correlated with the proliferation, development, or cell cycle progression of many protozoan parasites. Along these lines, T. brucei and Leishmania MAPKs have been described: mitogen-activated protein kinase (LMPK) of $L$. mexicana [119] and TbMAPK2 of T. brucei [39]. In the case of E. histolytica, two components of the MAPK signaling pathway have been identified in the E. histolytica genome [120]. MAPK belongs to the extracellular signal-regulated kinase (ERK) family, so it may conserve its biological role in regulating the response to the environment for cell proliferation [121] (Figure 1, (C)).

5.4. Growth Factors Signaling Pathway. This signaling pathway operates through phosphatidylinositol 3-kinase (PI3K) or PI4K and PI-related kinases with some functions in regulating cell proliferation, such as apoptosis, mitosis, cytokinesis, membrane trafficking, and cytoskeletal organization. The most important component, PI3K, generates the second messenger phosphatidylinositol-3,4,5-trisphosphate (PI3P) that in turn activates both phosphoinositide-dependent kinase 1 (PDK1) and protein kinase $\mathrm{B}(\mathrm{PKB})$ that translocate into the nucleus. PI3K confers the mobility needed for clathrin-coated membranes through the microtubule motor machinery [116, 122].

In this sense, PI3K contributes to sending information to the target of rapamycin (TOR) signaling pathway, named because it is inhibited by the drug rapamycin, which is a potent inhibitor of cell proliferation. TOR is a serine/threonine protein kinase, which operates as a nutrientsensitive cell cycle checkpoint controlling protein synthesis. The activity of TOR is switched off and cell proliferation ceases under conditions of low concentrations of amino acids or when energy is limiting. This kinase is organized into two complexes, TOR1 and TOR2.

A genetic screen of the T. brucei, T. cruzi, Leishmania major, L. braziliensis, L. infantum, and E. histolytica genomes established the presence of several PIKs and PI3Ks, so they have been proposed as a novel signaling pathway $[58,112]$.

In the kinase TOR, the functions are well conserved in eukaryotes with some differences in cellular localization. The presence of the TOR1 and TOR2 complexes in T. brucei and T. cruzi was described, and cellular localization was determined 
in order to define the function, because the localization of signaling molecules is related to their function and specificity. In T. brucei, TbTOR1 was observed inside the nucleus and TbTOR2 was associated with the endoplasmic reticulum and mitochondria. In T. cruzi, TcTOR1 was absent from the nucleus and was observed close to reservosomes, and TcTOR2 was found dispersed in the cytosol around TcTOR1. These differences in localization suggest a new function of the TOR complex as a result of the high genome plasticity observed in T. cruzi originating from different events of intragenic recombination [123]. Different localization could suggest new functions of TOR complexes (Figure 1, (D)).

Several PI3Ks [124, 125], 307 putative PK [120], or hybrid kinases [126], more than 43 putative tyrosine kinaseslinked receptors [120], and transmembrane kinases receptors (TMKs) that mediate responses to environment and immune evasion $[127,128]$ were identified in E. histolytica. Unfortunately, the role of these proteins in the endocytosis of $\mathrm{Tf}$ and signaling pathways has not been studied.

Further studies are necessary to comprehend the role of these proteins in order to understand the Fe acquisition system of Tf and Fe metabolism in these important parasites.

\section{Conclusion}

The importance of effective Fe uptake has been demonstrated for virulence in several pathogens, and although substantial progress has been made, there is surprisingly little information available about the signal transduction pathways induced by Tf endocytosis in order to obtain Fe. Although the broad picture suggests similarities with the mammalian host, there are many gaps in our understanding of these processes. The identification of signaling proteins will be useful to identify new factors that are essential for parasite adaptation to the host environment.

To date, it has been difficult to compare signal transduction processes in the studied organisms, but it is possible that they are very similar, and as was observed, this similitude may be conserved in intra- and extracellular parasites, despite the fact that they confront Fe absence in different ways.

The differences observed between several proteins and their equivalents in mammals could be used as therapeutic targets that may help treat diseases produced by these parasites, which has implications for biomedical research to develop new chemotherapeutic strategies.

\section{Conflict of Interests}

The authors declare that there is no conflict of interests regarding the publication of this paper.

\section{Acknowledgment}

This work was supported by CONACYT Grant 179251.

\section{References}

[1] E. D. Weinberg, "The hazards of iron loading," Metallomics, vol. 2, no. 11, pp. 732-740, 2010.
[2] J. Kaplan and D. M. Ward, "The essential nature of iron usage and regulation," Current Biology, vol. 23, no. 15, pp. R642-R646, 2013.

[3] A. Gudjoncik, C. Guenancia, M. Zeller, Y. Cottin, C. Vergely, and L. Rochette, "Iron, oxidative stress, and redox signaling in the cardiovascular system," Molecular Nutrition \& Food Research, vol. 58, no. 8, pp. 1721-1738, 2014.

[4] E. Griffiths, "Iron in biological Systems," in Iron and Infection, J. J. Bullen and E. Griffiths, Eds., John Wiley \& Sons, 1987.

[5] K. D. Krewulak and H. J. Vogel, "Structural biology of bacterial iron uptake," Biochimica et Biophysica Acta (BBA)Biomembranes, vol. 1778, no. 9, pp. 1781-1804, 2008.

[6] S. Waldvogel-Abramowski, G. Waeber, C. Gassner et al., "Physiology of iron metabolism," Transfusion Medicine and Hemotherapy, vol. 41, no. 3, pp. 213-221, 2014.

[7] S. Toyokuni, "Iron and thiols as two major players in carcinogenesis: friends or foes?" Frontiers in Pharmacology, vol. 5, article 200, 2014.

[8] A. Bezkorovainy, Biochemistry of Nonheme Iron, Plenum Press, New York, NY, USA, 1980.

[9] R. M. Ned, W. Swat, and N. C. Andrews, "Transferrin receptor 1 is differentially required in lymphocyte development," Blood, vol. 102, no. 10, pp. 3711-3718, 2003.

[10] K. Gkouvatsos, G. Papanikolaou, and K. Pantopoulos, "Regulation of iron transport and the role of transferrin," Biochimica et Biophysica Acta (BBA)_General Subjects, vol. 1820, no. 3, pp. 188-202, 2012.

[11] C. J. Parker Siburt, T. A. Mietzner, and A. L. Crumbliss, "FbpA-a bacterial transferrin with more to offer," Biochimica et Biophysica Acta - General Subjects, vol. 1820, no. 3, pp. 379392, 2012.

[12] Ø. Andersen, M. C. De Rosa, D. Pirolli, A. Tooming-Klunderud, P. E. Petersen, and C. André, "Polymorphism, selection and tandem duplication of transferrin genes in Atlantic cod (Gadus morhua)-conserved synteny between fish monolobal and tetrapod bilobal transferrin loci," BMC Genetics, vol. 12, no. 1, article 51, 2011.

[13] J. P. Gaffney and A. M. Valentine, "Beyond bilobal: transferrin homologs having unusual domain architectures," Biochimica et Biophysica Acta: General Subjects, vol. 1820, no. 3, pp. 212-217, 2012.

[14] A. D. Sheftel, A. B. Mason, and P. Ponka, "The long history of iron in the Universe and in health and disease," Biochimica et Biophysica Acta-General Subjects, vol. 1820, no. 3, pp. 161-187, 2012.

[15] L. A. Lambert, H. Perri, and T. J. Meehan, "Evolution of duplications in the transferrin family of proteins," Comparative Biochemistry and Physiology Part B: Biochemistry and Molecular Biology, vol. 140, no. 1, pp. 11-25, 2005.

[16] F. Bou-Abdallah and T. R. Terpstra, "The thermodynamic and binding properties of the transferrins as studied by isothermal titration calorimetry", Biochimica et Biophysica Acta (BBA)General Subjects, vol. 1820, no. 3, pp. 318-325, 2012.

[17] J. Chen and C. A. Enns, "Hereditary hemochromatosis and transferrin receptor 2," Biochimica et Biophysica Acta-General Subjects, vol. 1820, no. 3, pp. 256-263, 2012.

[18] G. J. Anderson and C. D. Vulpe, "Mammalian iron transport," Cellular and Molecular Life Sciences, vol. 66, no. 20, pp. 32413261, 2009. 
[19] C. I. Raje, S. Kumar, A. Harle, J. S. Nanda, and M. Raje, “The macrophage cell surface glyceraldehyde-3-phosphate dehydrogenase is a novel transferrin receptor," The Journal of Biological Chemistry, vol. 282, no. 5, pp. 3252-3261, 2007.

[20] J.-W. Kim and C. V. Dang, "Multifaceted roles of glycolytic enzymes," Trends in Biochemical Sciences, vol. 30, no. 3, pp. 142150, 2005.

[21] C. J. Jeffery, "Moonlighting proteins-an update," Molecular BioSystems, vol. 5, no. 4, pp. 345-350, 2009.

[22] J.-M. El Hage Chahine, M. Hémadi, and N.-T. Ha-Duong, "Uptake and release of metal ions by transferrin and interaction with receptor 1," Biochimica et Biophysica Acta-General Subjects, vol. 1820, no. 3, pp. 334-347, 2012.

[23] W. R. Harris, "Anion binding properties of the transferrins. Implications for function," Biochimica et Biophysica ActaGeneral Subjects, vol. 1820, no. 3, pp. 348-361, 2012.

[24] T. R. Daniels, E. Bernabeu, J. A. Rodríguez et al., “The transferrin receptor and the targeted delivery of therapeutic agents against cancer," Biochimica et Biophysica Acta: General Subjects, vol. 1820, no. 3, pp. 291-317, 2012.

[25] L. Sadowski, I. Pilecka, and M. Miaczynska, "Signaling from endosomes: location makes a difference," Experimental Cell Research, vol. 315, no. 9, pp. 1601-1609, 2009.

[26] D. Leonard, A. Hayakawa, D. Lawe et al., "Sorting of EGF and transferrin at the plasma membrane and by cargo-specific signaling to EEA1-enriched endosomes," Journal of Cell Science, vol. 121, no. 20, pp. 3445-3458, 2008.

[27] B. N. Kholodenko, "Cell-signalling dynamics in time and space," Nature Reviews Molecular Cell Biology, vol. 7, no. 3, pp. 165-176, 2006.

[28] M. Nairz, D. Haschka, E. Demetz, and G. Weiss, "Iron at the interface of immunity and infection," Frontiers in Pharmacology, vol. 5, 2014.

[29] M. Reyes-López, J. Serrano-Luna, C. Piña-Vázquez, and M. de la Garza, "Transferrin binding proteins as a means to obtain iron in parasitic protozoa," in Binding Protein, K. Abdelmohsen, Ed., InTech, Rijeka, Croatia, 2012.

[30] K. Haldar, C. L. Henderson, and G. A. M. Cross, "Identification of the parasite transferrin receptor of Plasmodium falciparum-infected erythrocytes and its acylation via 1,2-diacyl-snglycerol," Proceedings of the National Academy of Sciences of the United States of America, vol. 83, no. 22, pp. 8565-8569, 1986.

[31] M. H. Rodriguez and M. Jungery, "A protein on Plasmodium falciparum-infected erythrocytes functions as a transferrin receptor," Nature, vol. 324, no. 6095, pp. 388-391, 1986.

[32] R. Sutak, E. Lesuisse, J. Tachezy, and D. R. Richardson, "Crusade for iron: iron uptake in unicellular eukaryotes and its significance for virulence," Trends in Microbiology, vol. 16, no. 6, pp. 261-268, 2008.

[33] D. Steverding, Y. D. Stierhof, H. Fuchs, R. Tauber, and P. Overath, "Transferrin-binding protein complex is the receptor for transferrin uptake in Trypanosoma brucei," Journal of Cell Biology, vol. 131, no. 5, pp. 1173-1182, 1995.

[34] J. R. Corrêa, G. C. Atella, M. M. Batista, and M. J. Soares, "Transferrin uptake in Trypanosoma cruzi is impaired by interference on cytostome-associated cytoskeleton elements and stability of membrane cholesterol, but not by obstruction of clathrindependent endocytosis," Experimental Parasitology, vol. 119, no. 1, pp. 58-66, 2008.

[35] C. S. Voyiatzaki and K. P. Soteriadou, "Identification and isolation of the Leishmania transferrin receptor," Journal of Biological Chemistry, vol. 267, no. 13, pp. 9112-9117, 1992.
[36] M. Reyes-López, J. D. J. Serrano-Luna, E. Negrete-Abascal, N. León-Sicairos, A. L. Guerrero-Barrera, and M. De la Garza, "Entamoeba histolytica: transferrin binding proteins," Experimental Parasitology, vol. 99, no. 3, pp. 132-140, 2001.

[37] I. H. Gilbert, "Drug discovery for neglected diseases: molecular target-based and phenotypic approaches," Journal of Medicinal Chemistry, vol. 56, no. 20, pp. 7719-7726, 2013.

[38] M. P. Barrett and S. L. Croft, "Emerging paradigms in antiinfective drug design," Parasitology, vol. 141, no. 1, pp. 1-7, 2014.

[39] I. B. Müller, D. Domenicali-Pfister, I. Roditi, and E. Vassella, "Stage-specific requirement of a mitogen-activated protein kinase by Trypanosoma brucei," Molecular Biology of the Cell, vol. 13, no. 11, pp. 3787-3799, 2002.

[40] A. Maier and D. Steverding, "Low affinity of Trypanosoma brucei transferrin receptor to apotransferrin at $\mathrm{pH} 5$ explains the fate of the ligand during endocytosis," FEBS Letters, vol. 396, no. 1, pp. 87-89, 1996.

[41] D. Steverding, D. W. Sexton, N. Chrysochoidi, and F. Cao, "Trypanosoma brucei transferrin receptor can bind C-lobe and N-lobe fragments of transferrin," Molecular and Biochemical Parasitology, vol. 185, no. 2, pp. 99-105, 2012.

[42] C. Hertz-Fowler, L. M. Figueiredo, M. A. Quail et al., "Telomeric expression sites are highly conserved in Trypanosoma brucei," PLoS ONE, vol. 3, no. 10, Article ID e3527, 2008.

[43] D. Steverding, "The transferrin receptor of Trypanosoma brucei," Parasitology International, vol. 48, no. 3, pp. 191-198, 2000.

[44] E. Pays, "The variant surface glycoprotein as a tool for adaptation in African trypanosomes," Microbes and Infection, vol. 8, no. 3, pp. 930-937, 2006.

[45] G. W. Morgan, C. L. Allen, T. R. Jeffries, M. Hollinshead, and M. C. Field, "Developmental and morphological regulation of clathrin-mediated endocytosis in Trypanosoma brucei," Journal of Cell Science, vol. 114, no. 14, pp. 2605-2615, 2001.

[46] D. Steverding, D. W. Sexton, X. Wang, S. S. Gehrke, G. K. Wagner, and C. R. Caffrey, "Trypanosoma brucei: chemical evidence that cathepsin $\mathrm{L}$ is essential for survival and a relevant drug target," International Journal for Parasitology, vol. 42, no. 5, pp. 481-488, 2012.

[47] A. Mehlert, M. R. Wormald, and M. A. J. Ferguson, "Modeling of the N-glycosylated transferrin receptor suggests how transferrin binding can occur within the surface coat of Trypanosoma brucei," PLoS Pathogens, vol. 8, no. 4, Article ID e1002618, 2012.

[48] C. Cordon-Obras, J. Cano, D. González-Pacanowska, A. Benito, M. Navarro, and J.-M. Bart, "Trypanosoma brucei gambiense adaptation to different Mammalian Sera is associated with VSG expression site plasticity," PLoS ONE, vol. 8, no. 12, Article ID e85072, 2013.

[49] C. M. Batista, L. C. S. Medeiros, I. Eger, and M. J. Soares, "MAb CZP-315.D9: an antirecombinant cruzipain monoclonal antibody that specifically labels the reservosomes of Trypanosoma cruzi epimastigotes," BioMed Research International, vol. 2014, Article ID 714749, 9 pages, 2014.

[50] C. Bern, S. Kjos, M. J. Yabsley, and S. P. Montgomery, "Trypanosoma cruzi and Chagas' disease in the united states," Clinical Microbiology Reviews, vol. 24, no. 4, pp. 655-681, 2011.

[51] M. F. Lima and F. Villalta, "Trypanosoma cruzi receptors for human transferrin and their role," Molecular and Biochemical Parasitology, vol. 38, no. 2, pp. 245-252, 1990.

[52] I. Porto-Carreiro, M. Attias, K. Miranda, W. de Souza, and N. Cunha-E-Silva, "Trypanosoma cruzi epimastigote endocytic pathway: cargo enters the cytostome and passes through an 
early endosomal network before storage in reservosomes," European Journal of Cell Biology, vol. 79, no. 11, pp. 858-869, 2000.

[53] M. J. Soares, T. Souto-Padron, and W. De Souza, "Identification of a large pre-lysosomal compartment in the pathogenic protozoon Trypanosoma cruzi," Journal of Cell Science, vol. 102, no. 1, pp. 157-167, 1992.

[54] J. R. Corrêa, G. C. Atella, R. S. Menna-Barreto, and M. J. Soares, "Clathrin in Trypanosoma cruzi: in silico gene identification, isolation, and localization of protein expression sites," Journal of Eukaryotic Microbiology, vol. 54, no. 3, pp. 297-302, 2007.

[55] L. C. Kalb, Y. C. Antunes, C. Martin, I. Eger, S. Perdigao, and M. J. Soares, "Clathrin expression in Trypanosoma cruzi," BMC Cell Biology, vol. 15, article 23, 2014.

[56] I. Eger and M. J. Soares, "Endocytosis in Trypanosoma cruzi (Euglenozoa: Kinetoplastea) epimastigotes: visualization of ingested transferrin-gold nanoparticle complexes by confocal laser microscopy," Journal of Microbiological Methods, vol. 91, no. 1, pp. 101-105, 2012.

[57] G. M. Rocha, S. H. Seabra, K. R. de Miranda, N. Cunha-e-Silva, T. M. U. de Carvalho, and W. De Souza, "Attachment of flagellum to the cell body is important to the kinetics of transferrin uptake by Trypanosoma cruzi," Parasitology International, vol. 59, no. 4, pp. 629-633, 2010.

[58] D. Bahia, L. M. Oliveira, F. M. Lima et al., "The TryPIKinome of five human pathogenic trypanosomatids: Trypanosoma brucei, Trypanosoma cruzi, Leishmania major, Leishmania braziliensis and Leishmania infantum-New tools for designing specific inhibitors," Biochemical and Biophysical Research Communications, vol. 390, no. 3, pp. 963-970, 2009.

[59] P. Kaye and P. Scott, "Leishmaniasis: complexity at the hostpathogen interface," Nature Reviews Microbiology, vol. 9, no. 8, pp. 604-615, 2011.

[60] N. Courret, C. Fréhel, N. Gouhier et al., "Biogenesis of Leishmania-harbouring parasitophorus vacuoles following phagocytosis of the metacyclic promastigote or amastigote stages of the parasites," Journal of Cell Science, vol. 115, no. 11, pp. 2303-2316, 2002.

[61] I. Jacques, N. W. Andrews, and C. Huynh, "Functional characterization of LIT1, the Leishmania amazonensis ferrous iron transporter," Molecular and Biochemical Parasitology, vol. 170, no. 1, pp. 28-36, 2010.

[62] C. S. Voyiatzaki and K. P. Soteriadou, "Evidence of transferrin binding sites on the surface of Leishmania promastigotes," The Journal of Biological Chemistry, vol. 265, no. 36, pp. 2238022385, 1990.

[63] V. M. Borges, M. A. Vannier-Santos, and W. De Souza, "Subverted transferrin trafficking in Leishmania-infected macrophages," Parasitology Research, vol. 84, no. 10, pp. 811-822, 1998.

[64] D. G. Russell, S. Xu, and P. Chakraborty, "Intracellular trafficking and the parasitophorous vacuole of Leishmania mexicanainfected macrophages," Journal of Cell Science, vol. 103, no. 4, pp. 1193-1210, 1992.

[65] M. E. Wilson, T. S. Lewis, M. A. Miller, M. L. McCormick, and B. E. Britigan, "Leishmania chagasi: uptake of iron bound to lactoferrin or transferrin requires an iron reductase," Experimental Parasitology, vol. 100, no. 3, pp. 196-207, 2002.

[66] I. K. M. Ali, C. G. Clark, and W. A. Petri Jr., "Molecular epidemiology of amebiasis," Infection, Genetics and Evolution, vol. 8 , no. 5, pp. 698-707, 2008.
[67] M. Reyes-López, R. M. Bermúdez-Cruz, E. E. Avila, and M. De La Garza, "Acetaldehyde/alcohol dehydrogenase-2 (EhADH2) and clathrin are involved in internalization of human transferrin by Entamoeba histolytica," Microbiology, vol. 157, no. 1, pp. 209-219, 2011.

[68] B. H. Welter, R. R. Powell, R. C. Laughlin et al., "Entamoeba histolytica: comparison of the role of receptors and filamentous actin among various endocytic processes," Experimental Parasitology, vol. 113, no. 2, pp. 91-99, 2006.

[69] N. León-Sicairos, M. Reyes-López, A. Canizalez-Román et al., "Human hololactoferrin: endocytosis and use as an iron source by the parasite Entamoeba histolytica," Microbiology, vol. 151, no. 12, pp. 3859-3871, 2005.

[70] F. López-Soto, A. González-Robles, L. Salazar-Villatoro et al., "Entamoeba histolytica uses ferritin as an iron source and internalises this protein by means of clathrin-coated vesicles," International Journal for Parasitology, vol. 39, no. 4, pp. 417-426, 2009.

[71] A. Espinosa, G. Perdrizet, G. Paz-y-Miño C, R. Lanfranchi, and M. Phay, "Effects of iron depletion on Entamoeba histolytica alcohol dehydrogenase 2 (EhADH2) and trophozoite growth: implications for antiamoebic therapy," Journal of Antimicrobial Chemotherapy, vol. 63, no. 4, pp. 675-678, 2009.

[72] A. Tovy, R. S. Tov, R. Gaentzsch, M. Helm, and S. Ankri, "A new nuclear function of the Entamoeba histolytica glycolytic enzyme enolase: the metabolic regulation of cytosine-5 methyltransferase 2 (Dnmt2) activity," PLoS Pathogens, vol. 6, no. 2, Article ID e1000775, 2010.

[73] B. Modun, J. Morrissey, and P. Williams, "The staphylococcal transferrin receptor: a glycolytic enzyme with novel functions," Trends in Microbiology, vol. 8, no. 5, pp. 231-237, 2000.

[74] S. Bergmann, M. Rohde, and S. Hammerschmidt, "Glyceraldehyde-3-phosphate dehydrogenase of Streptococcus pneumoniae is a surface-displayed plasminogen-binding protein," Infection and Immunity, vol. 72, no. 4, pp. 2416-2419, 2004.

[75] H. W. Platta and H. Stenmark, "Endocytosis and signaling," Current Opinion in Cell Biology, vol. 23, no. 4, pp. 393-403, 2011.

[76] A. Sorkin and M. von Zastrow, "Endocytosis and signalling: intertwining molecular networks," Nature Reviews Molecular Cell Biology, vol. 10, no. 9, pp. 609-622, 2009.

[77] M. Miaczynska, L. Pelkmans, and M. Zerial, "Not just a sink: endosomes in control of signal transduction," Current Opinion in Cell Biology, vol. 16, no. 4, pp. 400-406, 2004.

[78] S. Polo and P. P. Di Fiore, "Endocytosis conducts the cell signaling orchestra," Cell, vol. 124, no. 5, pp. 897-900, 2006.

[79] M. von Zastrow and A. Sorkin, "Signaling on the endocytic pathway," Current Opinion in Cell Biology, vol. 19, no. 4, pp. 436445, 2007.

[80] I. Gaidarov and J. H. Keen, "Membrane targeting of endocytic adaptors: cargo and lipid do it together," Developmental Cell, vol. 8, no. 6, pp. 801-802, 2005.

[81] G. Rohde, D. Wenzel, and V. Haucke, "A phosphatidylinositol $(4,5)$-bisphosphate binding site within mu2-adaptin regulates clathrin-mediated endocytosis," The Journal of Cell Biology, vol. 158, no. 2, pp. 209-214, 2002.

[82] A. E. Kruchten, E. W. Krueger, Y. Wang, and M. A. McNiven, "Distinct phospho-forms of cortactin differentially regulate actin polymerization and focal adhesions," American Journal of Physiology: Cell Physiology, vol. 295, no. 5, pp. C1113-C1122, 2008. 
[83] J. A. Head, D. Jiang, M. Li et al., "Cortactin tyrosine phosphorylation requires Racl activity and association with the cortical actin cytoskeleton," Molecular Biology of the Cell, vol. 14, no. 8, pp. 3216-3229, 2003.

[84] J. Zhu, D. Yu, X.-C. Zeng, K. Zhou, and X. Zhan, "Receptormediated endocytosis involves tyrosine phosphorylation of cortactin," Journal of Biological Chemistry, vol. 282, no. 22, pp. 16086-16094, 2007.

[85] H. Cao, J. Chen, E. W. Krueger, and M. A. McNiven, "Srcmediated phosphorylation of dynamin and cortactin regulates the 'constitutive' endocytosis of transferrin," Molecular and Cellular Biology, vol. 30, no. 3, pp. 781-792, 2010.

[86] L. Pelkmans, E. Fava, H. Grabner et al., "Genome-wide analysis of human kinases in clathrin- and caveolae/raft-mediated endocytosis," Nature, vol. 436, no. 7047, pp. 78-86, 2005.

[87] J. Rink, E. Ghigo, Y. Kalaidzidis, and M. Zerial, "Rab conversion as a mechanism of progression from early to late endosomes," Cell, vol. 122, no. 5, pp. 735-749, 2005.

[88] M. G. Roth, "Phosphoinositides in constitutive membrane traffic," Physiological Reviews, vol. 84, no. 3, pp. 699-730, 2004.

[89] M. Lakadamyali, M. J. Rust, and X. Zhuang, "Ligands for clathrin-mediated endocytosis are differentially sorted into distinct populations of early endosomes," Cell, vol. 124, no. 5, pp. 997-1009, 2006.

[90] P. Van Der Sluijs, M. Hull, L. A. Huber, P. Mâle, B. Goud, and I. Mellman, "Reversible phosphorylation-dephosphorylation determines the localization of rab4 during the cell cycle," The EMBO Journal, vol. 11, no. 12, pp. 4379-4389, 1992.

[91] C. T. Eggers, J. C. Schafer, J. R. Goldenring, and S. S. Taylor, "D-AKAP2 interacts with Rab4 and Rabll throughi its RGS domains and regulates transferrin receptor recycling," Journal of Biological Chemistry, vol. 284, no. 47, pp. 32869-32880, 2009.

[92] S. X. Lin, B. Grant, D. Hirsh, and F. R. Maxfield, "Rme-1 regulates the distribution and function of the endocytic recycling compartment in mammalian cells," Nature Cell Biology, vol. 3, no. 6, pp. 567-572, 2001.

[93] F. R. Maxfield and T. E. McGraw, "Endocytic recycling," Nature Reviews Molecular Cell Biology, vol. 5, no. 2, pp. 121-132, 2004.

[94] S. Pant, M. Sharma, K. Patel, S. Caplan, C. M. Carr, and B. D. Grant, "AMPH-1/Amphiphysin/Binl functions with RME1/Ehd1 in endocytic recycling," Nature Cell Biology, vol. 11, no. 12, pp. 1399-1410, 2009.

[95] C. J. Traer, A. C. Rutherford, K. J. Palmer et al., "SNX4 coordinates endosomal sorting of TfnR with dynein-mediated transport into the endocytic recycling compartment," Nature Cell Biology, vol. 9, no. 12, pp. 1370-1380, 2007.

[96] S. K. Rayala, P. Den Hollander, B. Manavathi et al., "Essential role of KIBRA in co-activator function of dynein light chain 1 in mammalian cells," Journal of Biological Chemistry, vol. 281, no. 28, pp. 19092-19099, 2006.

[97] R. Prekeris, J. Klumperman, Y. A. Chen, and R. H. Scheller, "Syntaxin 13 mediates cycling of plasma membrane proteins via tubulovesicular recycling endosomes," The Journal of Cell Biology, vol. 143, no. 4, pp. 957-971, 1998.

[98] C. Gabernet-Castello, J. B. Dacks, and M. C. Field, “The single ENTH-domain protein of trypanosomes; endocytic functions and evolutionary relationship with epsin," Traffic, vol. 10, no. 7, pp. 894-911, 2009.

[99] M. Kabiri and D. Steverding, "Studies on the recycling of the transferrin receptor in Trypanosoma brucei using an inducible gene expression system," European Journal of Biochemistry, vol. 267, no. 11, pp. 3309-3314, 2000.
[100] A. Pal, B. S. Hall, T. R. Jeffries, and M. C. Field, "Rab5 and Rabll mediate transferrin and anti-variant surface glycoprotein antibody recycling in Trypanosoma brucei," Biochemical Journal, vol. 374, no. 2, pp. 443-451, 2003.

[101] J. R. Araripe, F. Pereira Ramos, N. L. Cunha E Silva et al., "Characterization of a RAB5 homologue in Trypanosoma cruzi," Biochemical and Biophysical Research Communications, vol. 329, no. 2, pp. 638-645, 2005.

[102] S. M. de Mendonça, J. L. N. da Silva, N. C. E-Silva, W. de Souza, and U. G. Lopes, "Characterization of a Rabll homologue in Trypanosoma cruzi," Gene, vol. 243, no. 1-2, pp. 179-185, 2000.

[103] B. Hall, C. L. Allen, D. Goulding, and M. C. Field, "Both of the Rab5 subfamily small GTPases of Trypanosoma brucei are essential and required for endocytosis," Molecular and Biochemical Parasitology, vol. 138, no. 1, pp. 67-77, 2004.

[104] B. S. Hall, E. Smith, W. Langer, L. A. Jacobs, D. Goulding, and M. C. Field, "Developmental variation in Rabll-dependent trafficking in Trypanosoma brucei," Eukaryotic Cell, vol. 4, no. 5, pp. 971-980, 2005.

[105] L. A. Temesvari, E. N. Harris, S. L. Stanley Jr., and J. A. Cardelli, "Early and late endosomal compartments of Entamoeba histolytica are enriched in cysteine proteases, acid phosphatase and several Ras-related Rab GTPases," Molecular and Biochemical Parasitology, vol. 103, no. 2, pp. 225-241, 1999.

[106] G. C. McGugan Jr. and L. A. Temesvari, "Characterization of a Rabll-like GTPase, EhRab1l, of Entamoeba histolytica," Molecular and Biochemical Parasitology, vol. 129, no. 2, pp. 137146, 2003.

[107] Y. Saito-Nakano, T. Yasuda, K. Nakada-Tsukui, M. Leippe, and T. Nozaki, "Rab5-associated vacuoles play a unique role in phagocytosis of the enteric protozoan parasite Entamoeba histolytica," The Journal of Biological Chemistry, vol. 279, no. 47, pp. 49497-49507, 2004.

[108] K. Nakada-Tsukui, Y. Saito-Nakano, V. Ali, and T. Nozaki, "A retromerlike complex is a novel Rab7 effector that is involved in the transport of the virulence factor cysteine protease in the enteric protozoan parasite Entamoeba histolytica," Molecular Biology of the Cell, vol. 16, no. 11, pp. 5294-5303, 2005.

[109] B. N. Mitra, Y. Saito-Nakano, K. Nakada-Tsukui, D. Sato, and T. Nozaki, "Rab11B small GTPase regulates secretion of cysteine proteases in the enteric protozoan parasite Entamoeba histolytica," Cellular Microbiology, vol. 9, no. 9, pp. 2112-2125, 2007.

[110] S. B. Singh, R. Tandon, G. Krishnamurthy et al., "Rab5-mediated endosome-endosome fusion regulates hemoglobin endocytosis in Leishmania donovani," The EMBO Journal, vol. 22, no. 21, pp. 5712-5722, 2003.

[111] R. Javier-Reyna, V. I. Hernández-Ramírez, A. González-Robles, I. Galván-Mendoza, C. Osorio-Trujillo, and P. Talamás-Rohana, "Rab7 and actin cytoskeleton participate during mobilization of $\beta 1 E H F N R$ in fibronectin-stimulated Entamoeba histolytica trophozoites," Microscopy Research and Technique, vol. 75, no. 3, pp. 285-293, 2012.

[112] J. Tolstrup, E. Krause, E. Tannich, and I. Bruchhaus, "Proteomic analysis of Entamoeba histolytica," Parasitology, vol. 134, no. 2, pp. 289-298, 2007.

[113] V. K. Srivastava, M. Chandra, and S. Datta, "Crystallization and preliminary X-ray analysis of RabX3, a tandem GTPase from Entamoeba histolytica," Acta Crystallographica Section F, vol. 70, no. 7, pp. 933-937, 2014.

[114] F. Nakatsu, R. M. Perera, L. Lucast et al., "The inositol 5phosphatase SHIP2 regulates endocytic clathrin-coated pit 
dynamics," The Journal of Cell Biology, vol. 190, no. 3, pp. 307315, 2010.

[115] N. Abe, T. Inoue, T. Galvez, L. Klein, and T. Meyer, "Dissecting the role of $\operatorname{PtdIns}(4,5) P_{2}$ in endocytosis and recycling of the transferrin receptor," Journal of Cell Science, vol. 121, no. 9, pp. 1488-1494, 2008.

[116] J. L. Martys, C. Wjasow, D. M. Gangi, M. C. Kielian, T. E. McGraw, and J. M. Backer, "Wortmannin-sensitive trafficking pathways in Chinese hamster ovary cells: differential effects on endocytosis and lysosomal sorting," Journal of Biological Chemistry, vol. 271, no. 18, pp. 10953-10962, 1996.

[117] S. Subramanya, F. C. Hardin, D. Steverding, and K. MensaWilmot, "Glycosylphosphatidylinositol-specific phospholipase $\mathrm{C}$ regulates transferrin endocytosis in the African trypanosome," Biochemical Journal, vol. 417, no. 3, pp. 685-694, 2009.

[118] S. Subramanya and K. Mensa-Wilmot, "Diacylglycerol-stimulated endocytosis of transferrin in trypanosomatids is dependent on tyrosine kinase activity," PLOS ONE, vol. 5, no. 1, Article ID e8538, 2010.

[119] M. Wiese, "A mitogen-activated protein (MAP) kinase homologue of Leishmania mexicana is essential for parasite survival in the infected host," The EMBO Journal, vol. 17, no. 9, pp. 26192628, 1998.

[120] K. Anamika, A. Bhattacharya, and N. Srinivasan, "Analysis of the protein kinome of Entamoeba histolytica," Proteins: Structure, Function and Genetics, vol. 71, no. 2, pp. 995-1006, 2008.

[121] D. Ray, S. Dutta, S. Banerjee, R. Banerjee, and S. Raha, "Identification, structure, and phylogenetic relationships of a mitogenactivated protein kinase homologue from the parasitic protist Entamoeba histolytica," Gene, vol. 346, pp. 41-50, 2005.

[122] Y. Zhao, I. Gaidarov, and J. H. Keen, "Phosphoinositide 3-kinase C $2 \alpha$ links clathrin to microtubule-dependent movement," The Journal of Biological Chemistry, vol. 282, no. 2, pp. 1249-1256, 2007.

[123] P. Oliveira, F. M. Lima, M. C. Cruz et al., "Trypanosoma cruzi: genome characterization of phosphatidylinositol kinase gene family (PIK and PIK-related) and identification of a novel PIK gene," Infection, Genetics and Evolution, vol. 25, pp. 157-165, 2014.

[124] A. B. Koushik, B. H. Welter, M. L. Rock, and L. A. Temesvari, "A genomewide overexpression screen identifies genes involved in the phosphatidylinositol 3-kinase pathway in the human protozoan parasite Entamoeba histolytica," Eukaryotic Cell, vol. 13, no. 3, pp. 401-411, 2014.

[125] S. Shrimal, A. Saha, S. Bhattacharya, and A. Bhattacharya, "Lipids induce expression of serum-responsive transmembrane kinase EhTMKB1-9 in an early branching eukaryote Entamoeba histolytica," Scientific Reports, vol. 2, article 333, 2012.

[126] J. Martin, K. Anamika, and N. Srinivasan, "Classification of protein kinases on the basis of both kinase and non-kinase regions," PLoS ONE, vol. 5, no. 9, Article ID e12460, 2010.

[127] A. Mehra, J. Fredrick, W. A. Petri Jr., S. Bhattacharya, and A. Bhattacharya, "Expression and function of a family of transmembrane kinases from the protozoan parasite Entamoeba histolytica," Infection and Immunity, vol. 74, no. 9, pp. 5341-5351, 2006.

[128] S. N. Buss, S. Hamano, A. Vidrich et al., "Members of the Entamoeba histolytica transmembrane kinase family play nonredundant roles in growth and phagocytosis," International Journal for Parasitology, vol. 40, no. 7, pp. 833-843, 2010. 

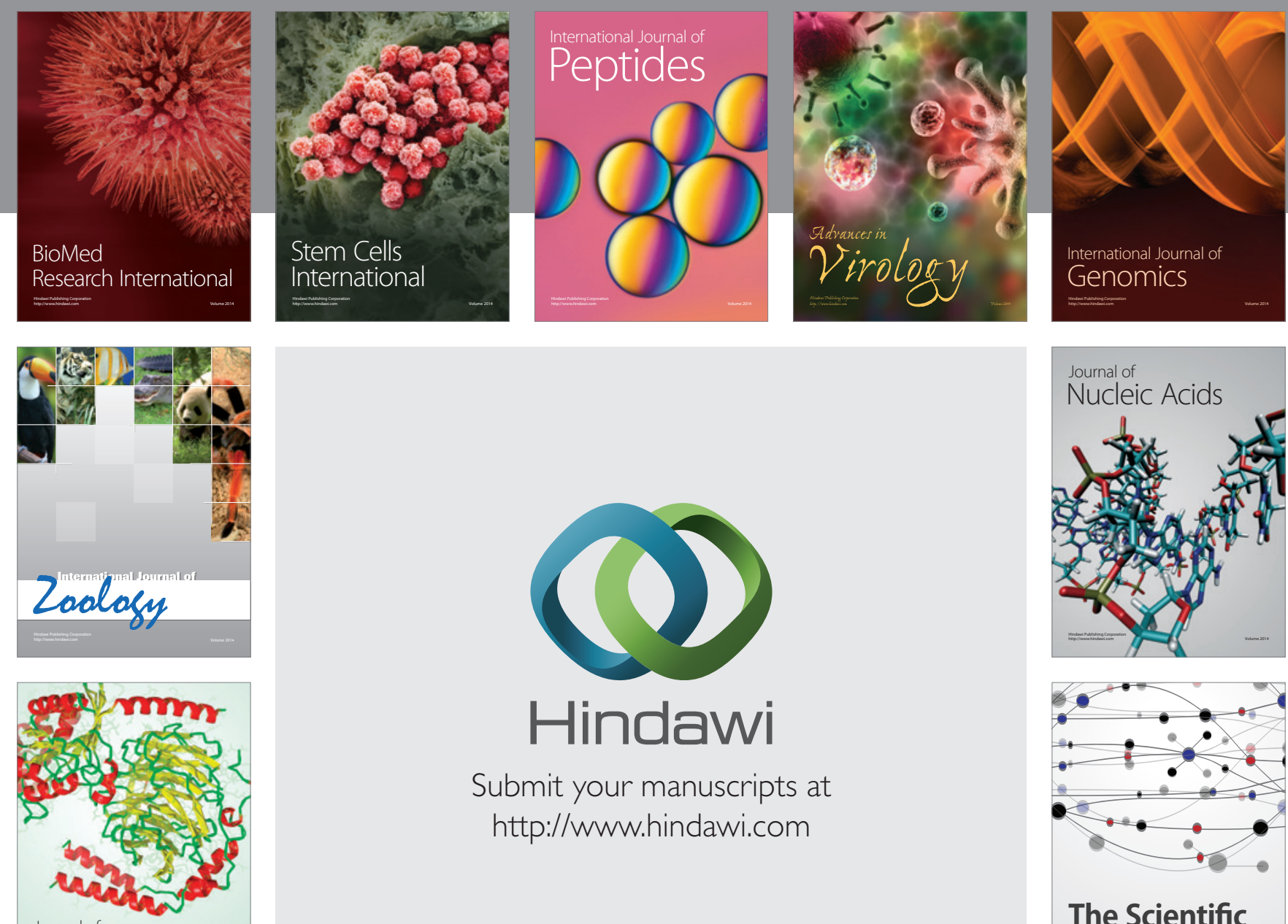

Submit your manuscripts at

http://www.hindawi.com

Journal of
Signal Transduction
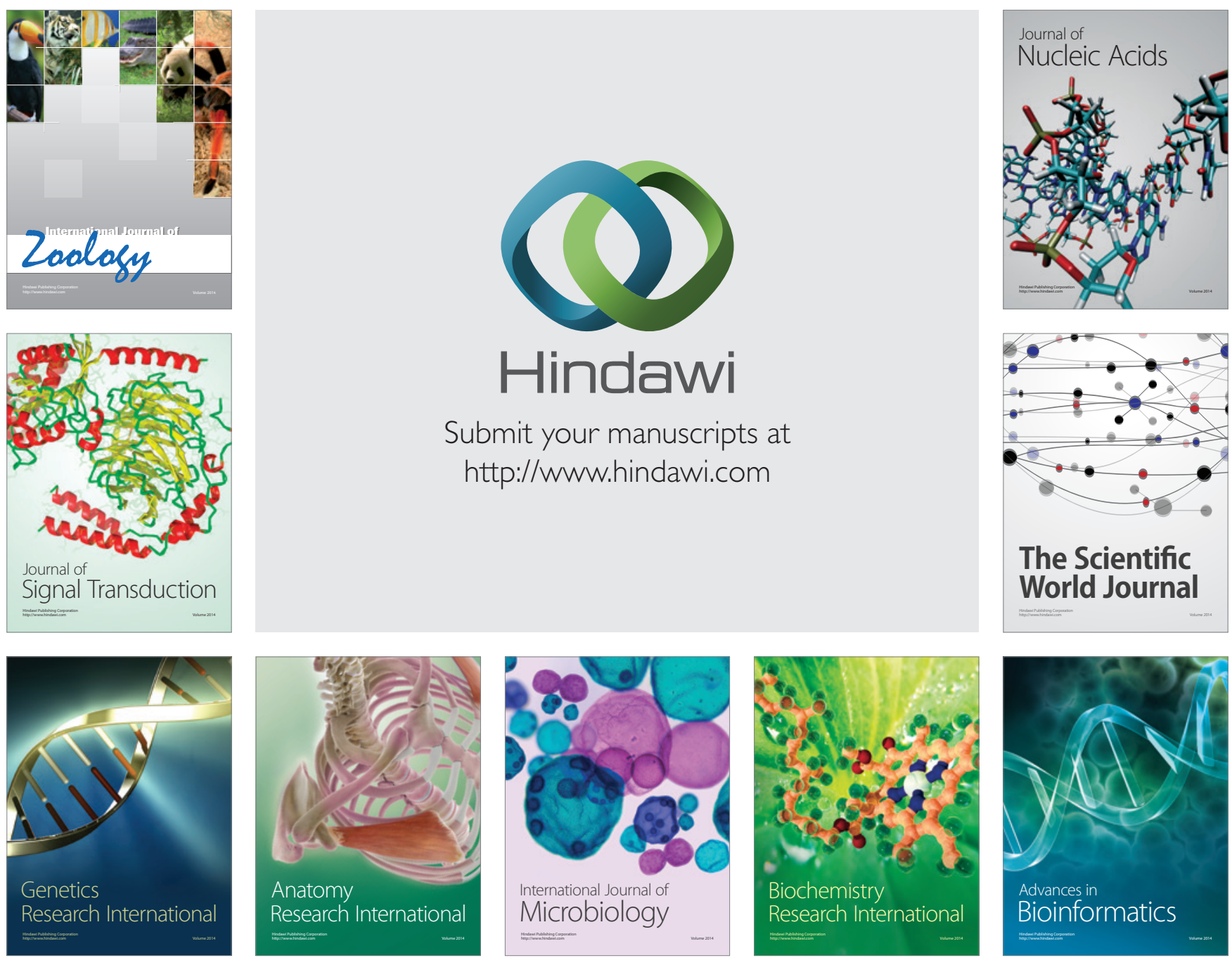

The Scientific World Journal
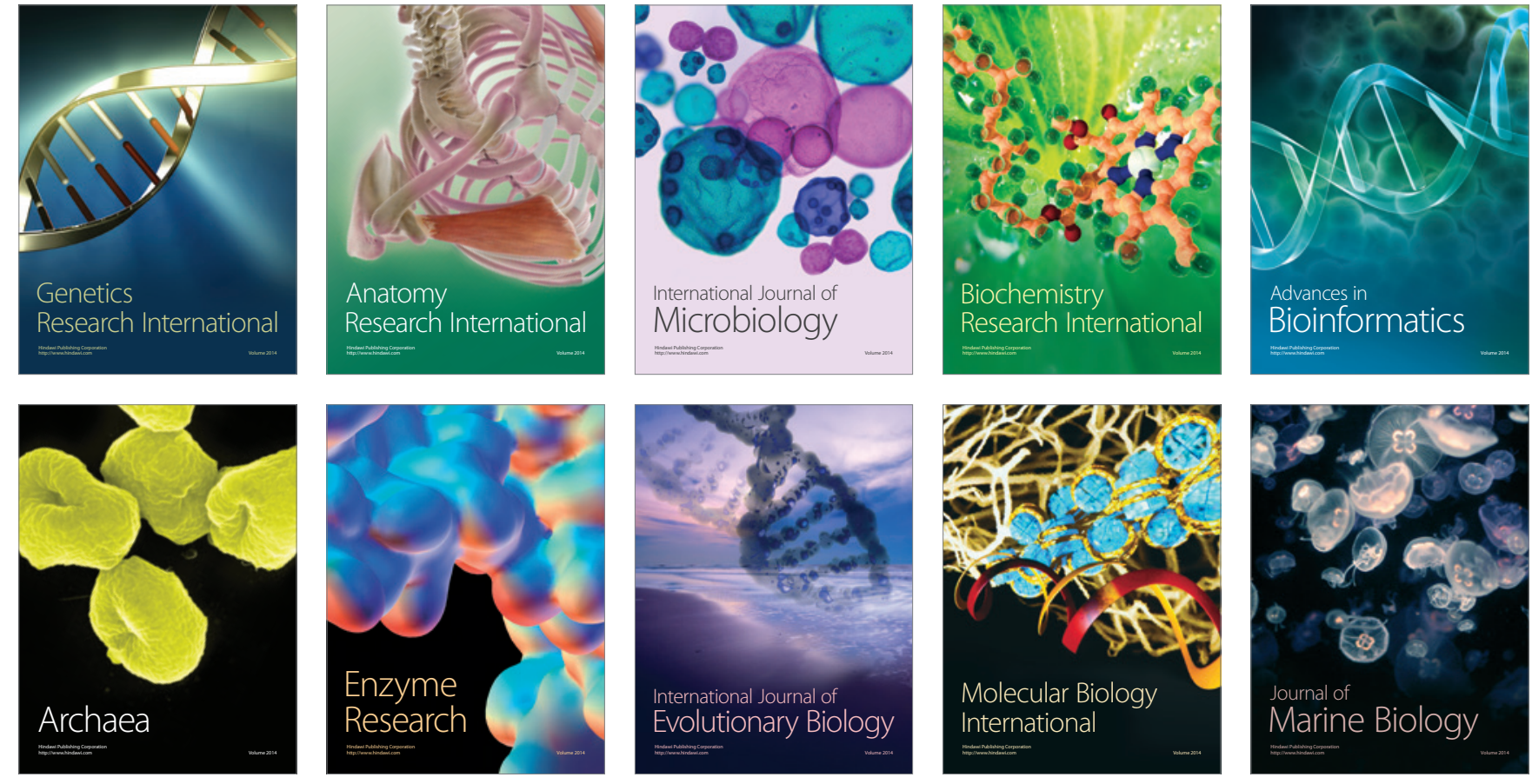